\title{
Intralobar pulmonary sequestration in conjunction with bronchial isomerism
}

\author{
KRISHNA K MOHAN, NEIL KRAMER, MITCHELL L MARGOLIS, ROBERT M STEINER, \\ HERBERT E COHN
}

\author{
From the Division of Pulmonary Diseases and Departments of Medicine, Radiology, and Thoracic Surgery, \\ Thomas Jefferson University Hospital, Philadelphia, Pennsylvania
}

\begin{abstract}
Pulmonary sequestration is an uncommon congenital anomaly characterised by a mass of non-functional, dysplastic lung parenchyma that docs not communicate with the normal tracheobronchial tree. Such an anomaly commonly receives its blood supply from the systemic circulation. The sequestered pulmonary segment is considered to be intralobar if it is enclosed within the common pleura enveloping the normal lung and extralobar if it has its own separate pleural investment. Intralobar pulmonary sequestration is only rarely associated with other congenital anomalies, whereas a large proportion of cases of extralobar sequestration are associated with diaphragmatic hernias and other congenital anomalies.'

This case report describes a patient with an intralobar sequestration on the right side who also had a left-sided bronchial anatomy on the right (bronchial isomerism). To our knowledge this association has not been previously reported.
\end{abstract}

\section{Case report}

A 29-year-old white woman who worked as an insurance executive was admitted to Thomas Jefferson University Hospital because of recurring haemoptysis. Blood-streaked sputum had been noticed by the patient over several years. There were no other symptoms referable to the respiratory system or cardiovascular system. She did not smoke cigarettes. Physical examination showed nothing abnormal.

The initial chest radiograph showed a well-demarcated, round soft-tissue density in the region of the medial basal segment of the right lower lobe, and the pulmonary vessels to the right lower lobe appeared abnormal. Flexible fibreoptic bronchoscopy showed no bleeding sites or endobronchial lesions up to the fourth-generation bronchi. The bronchial anatomy on the right side, however, was a mirror image of that on the left. A relatively long right main-stem bronchus led to upper-lobe and lower-lobe bronchi; the upper-lobe bronchus led to a middle-lobe and a true upper-lobe bronchus. Each of the lobar bronchi had two segmental divisions-an isomerism of the left-sided anatomy with upper-lobe and lingular counterparts. Inspection of the right lower lobe showed hypoplasia of the lobar bronchus with regional inflammation. One apical and two of the four basal segmental bronchi could be identified,

Address for reprint requests: Dr KK Mohan, Division of Pulmonary Disease, Thomas Jefferson University Hospital, Philadelphia, PA 19107, USA. but these appeared to be rotated and displaced. Selective bronchography on the right side confirmed left-sided pulmonary isomerism (fig $1 a$ and $1 b$ ). An abdominal aortogram showed that an aberrant artery arising from the abdominal aorta, cephalad to the coeliac axis, supplied the sequestered lung mass. The aberrant artery had a large aneurysmal dilatation in its course (fig 2 ). The venous return from the sequestered lung segment was through a cluster of veins into the hepatic vein via a defect in the diaphragm.

A clinical diagnosis of pulmonary sequestration with pulmonary bronchial isomerism was made. Exploratory thoracotomy showed a bilobed right lung, the upper lobe providing a lingula counterpart. An intralobar sequestration was located in the medial portion of the right lower lobe with its aberrant systemic arterial supply arising from below the diaphragm. The sequestrated lung segment was removed with its aneurysmal feeding vessel. The patient tolerated the procedure well and made a satisfactory recovery.

\section{Discussion}

Intralobar pulmonary sequestrations constitute $0 \cdot 2-6 \cdot 4 \%$ of all congenital pulmonary malformations. In a review of 400 cases of intralobar pulmonary sequestration Savic et al noted a concomitant congenital anomaly in only $13.7 \%$ of the cases. In no case was bronchial isomerism identified, nor do other reports of pulmonary sequestration ${ }^{2-9}$ mention coexisting bronchial isomerism.

Four types of bronchial isomerism have been described. ${ }^{5}$ So far none of these has been reported to be associated with pulmonary sequestration. Type I, which predominates in males, consists of bilateral trilobed lungs and is associated with asplenia, malrotation of the gut, and congenital cardiovascular anomalies that include transposition of the great vessels, atrial septal defects, ventricular septal defects, and right-sided aortic arches. Type II bronchial isomerism consists of anisosplenia associated with the other features of type I isomerism. Type III combines bilateral bilobed lungs with polysplenia, gut malrotation, and congenital heart disease, and appears to have no sex predilection. Type IV bronchial isomerism syndrome occurs most often in females and includes bilobed lobes with gut malrotation, anisosplenia, and a double outlet from the right ventricle. Our patient' declined to , have / a liver or spleen scan but the aortographic study did show a normal splenic artery and left gastric arteries arising from the coeliac axis.

Bronchial isomerism almost never causes symptoms. 

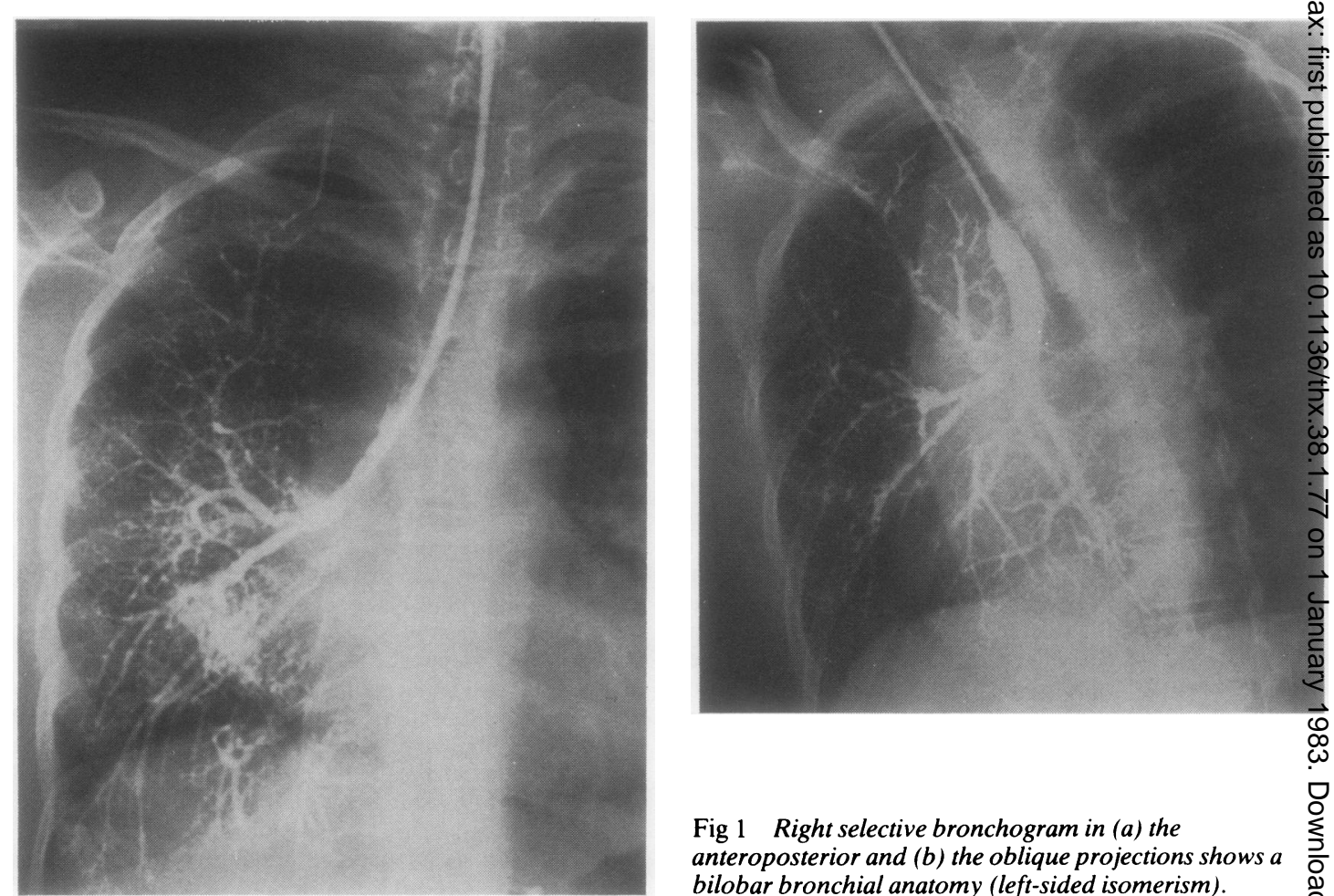

Fig 1 Right selective bronchogram in (a) the anteroposterior and (b) the oblique projections shows a bilobar bronchial anatomy (left-sided isomerism).

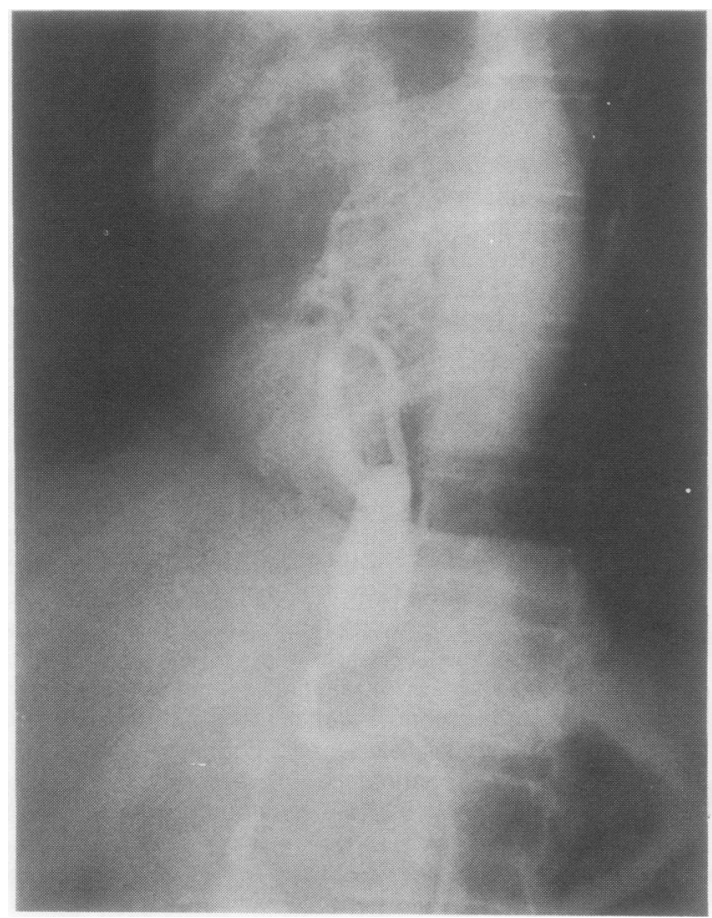

Fig 2 Selective arteriogram illustrating the aberrant arterg supplying the sequestered segment. The saccular aneurysm seen in the mid-portion of the aberrant artery. 
Pulmonary sequestrations, on the other hand, when symptomatic, may lead to haemoptysis or recurrent infections in the sequestered lung segment. In either case early resection of the sequestration is the preferred treatment.

The developmental origins of these uncommon congenital anomalies are of interest to embryologists, bronchoscopists, and surgeons. Intralobar pulmonary sequestrations develop from accessory lung buds, which are enveloped by the normal lung and pleura during their caudal migration. On the other hand, bronchial isomerism as a phenomenon is more difficult to explain-presumably the bronchial pouch, budding off the laryngotracheal cleft before the 12 th week of intrauterine life, fails to subdivide normally.

Clinicians must be aware of the multiple associated congenital anomalies of the lung, gut, abdominal viscera, heart, and blood vessels so that they can diagnose and treat any associated illnesses.

\section{References}

' Savic B, Birtel FJ, Tholen W, Funke HD, Knoche R.
Lung sequestrations: report of seven cases and review of published cases. Thorax 1979;34:98-101.

${ }^{2}$ Weekly Clinicopathological exercises. Pulmonary sequestration. N Engl J Med 1981;304:1090-6.

${ }^{3}$ O'Mara CX, Baker RR, Jeyasinham K. Pulmonary sequestration. Surg Gyn Obst 1978;147:609-16.

${ }^{4}$ Landing $\mathrm{BH}$. Congenital malformations and genetic disorders of the respiratory tract (state of the art). Am Rev Respir Dis 1979;120:151-85.

${ }^{5}$ Szekely E, Farkas E. Pediatric bronchology. University Park Press, 1978.

- Fraser RG, Pare JA. Diagnosis of diseases of the chest. Vol 1. Philadelphia: WB Saunders, 1977:602-28.

${ }^{7}$ Landing BH, Lawrence TYK, Rayne VC jun, Wells TR. Bronchial anatomy in syndromes with abnormal visceral situs, abnormal spleen and congenital heart disease. Am J Cardiol 1971;28:456-62.

${ }^{8}$ Gerle RD, Jaretzki A, Ashley CA, Berne SA. Congenital bronchopulmonary foregut malformation: pulmonary sequestration communicating with the gastrointestinal tract. N Engl J Med 1968;287:1413-8.

9 Tonkin ILD, Allen RG, Riggs W, Satterwhite C. Double aortic arch associated with pulmonary sequestration. Cardiovasc Intervent Radiol 1981;4:264-7. 